\title{
7
}

\section{Service-Logic Rather than Product-Logic}

Companies conduct services for their customers, whether they do so by means of physical products or not. Sustainable business can be furthered by companies embracing a service-logic across all types of products. This implies thinking in terms of access over ownership, whether we are talking about sharing services, streaming services or leasing-like payment models. By building business models based on service-logic, companies can contribute to improved capacity utilization and less resource waste.

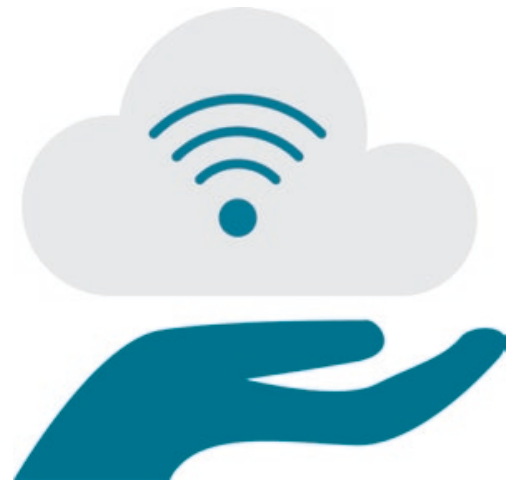

Fig. 7.1 Service-logic Rather than Product-logic

(C) The Author(s) 2018

S. Jørgensen, L. J. T. Pedersen, RESTART Sustainable Business Model Innovation, Palgrave Studies in Sustainable Business In Association with Future Earth, https://doi.org/10.1007/978-3-319-91971-3_7 


\subsection{At Your Service}

Every time Apple releases a new iPhone, people tend to drop their old smartphones on the ground or into the sea. The explosion of insurance claims from iPhone owners therefore surge exactly in the days ahead of a new model release (Fig. 7.1).

In this way, of course, people give themselves a reason to buy the latest iPhone model. Apple is obviously pleased at selling new phones. At the same time, however, the company finds it increasingly difficult to obtain raw materials for its new devices, and it has understood that old devices contain a number of resources that can be reused. It is obviously unfortunate for the environment that the resources inside old devices go astray, and we know that, for example, in Norway, only three of ten mobile phones are returned for recycling when the owners replace them.

A few years ago, Apple therefore introduced the "iPhone Upgrade Program"- a service that has since been copied by many other operators. It is a service that gives customers access to a new iPhone whenever they want, and they pay a monthly subscription fee. Apple thus goes from a business model in which the phone is sold to the customer (based on ownership) to a business model that provides customers access to the newest phones at any time (based on access and functionality). In addition, this business model gives the company access to old, used devices (so-called urban mining), which allows them the option of either renting them out again as-is or in refurbished versions or reusing components in the production of new devices. Not at least, the new business model has the advantageous characteristic that it largely provides a "lock-in" of customers to Apple's iPhones, which is also beneficial from a profitability standpoint (see, e.g., Dhebar 2016).

Apple achieves these benefits by introducing a service-logic in its business model, in place of a more traditional product-logic (cf. Lusch and Vargo 2012). Thus, Apple is changing the way it creates, delivers and captures value. The idea is that customer satisfaction will increase because of easy access to the latest models without the need to buy a new device. 
In doing so, Apple has turned the product iPhone into a service: paying for access to the latest iPhone model at any time. Apple may in turn capitalize on its "harvested" old devices by leasing them again to new customers, refurbishing them or reusing their components.

The new iPhone models are, unlike previous generations of iPhones, designed in such a way that they can be dismantled for reuse relatively easily. Apple has even developed robots that can dismantle used devices easily and effectively. Such devices contain several valuable resources like gold, lead and platinum. In 2014, Apple harvested a total of 40,000 tons of electronic waste, and the scope of its harvesting is on the increase. Apple's new business model is obviously inspired by the so-called circular economy, which is the topic of the next chapter, and it builds such a circular model in part by moving from a product-logic to a service-logic (see, e.g., Bocken et al. 2014, 2016).

\section{What Do We Mean by Service-Logic?}

In recent years, academics and business managers alike have opened their eyes to the service economy. Services largely dominate economic value creation in industrialized countries, to such an extent, in fact, that these countries should perhaps rather be called service economies than industrialized economies (cf. World Bank 2015). In addition, there is an increasing recognition that knowledge is scarce on how to build profitable, service-based business models (e.g., Kastalli and Van Looy 2013; Baines et al. 2009). We use the concept to denote not only services as service providers, in the traditional sense, offer them. It also comprises how products like smartphones, cars and clothes can be understood as services. This implies emphasizing that whatever is delivered to the customer acts as a service that solves a problem for the customer, even when it is done by means of a physical product to which the customer gets access (Lusch and Vargo 2012; Bocken et al. 2014).

There are many examples of products made into services, such as the iPhone Upgrade Program and Filippa K's sharing-economic model for the rental of fashion wear that customers would otherwise have had to 
purchase. Companies that sell products can also apply service-logic to enhance their value creation by offering additional services. Many firms now aim to sell more robust and durable products that can be repaired, but this runs the risk of reducing profitability because they end up selling fewer products to each customer. To remain profitable, the companies must recoup this revenue by selling additional services to their customers (see, e.g., Mont 2002; Tukker 2004). Apple is thus far from alone in developing a business model in which services are an important component.

Rolls Royce, for instance, offers its products such as aircraft engines as a service rather than a product (see, e.g., $\mathrm{Ng}$ et al. 2012). Hence, the company retains ownership of the product while its customers use it, and at any given time offers maintenance on the engines. Rolls Royce commits to keeping the aircraft engines in operation at all times, and the payment model is such that the customer pays for the time the engine is running, for the duration of the contract. Such a change in the company's offering usually requires a new business model. With regard to the profitability, the challenge with such a service-based business model is that it may be more expensive than a business model in which the company "waves goodbye" to the product when the customer buys it. Instead, this business model requires that Rolls Royce has staff who can provide the necessary service that follows from such a value proposition, even after the customer has started using the product. This requires an entirely different set of resources and competences than did the traditional business model, and it implies that the company must capture value in a different way than through conventional sales transactions.

\section{The Sharing Economy as Service-Logic}

In the next chapter, we will explore the circular economy, wherein a basic idea is that waste is simply resources gone astray (e.g., Stahel 2016). However, resources can go astray long before they end up in the scrap heap. For example, a drill is used on average only 13 minutes of 
its lifetime; our cars stand still on average 23 hours a day and when they are used, they are less than half full; and many people have houses, apartments and rooms available all or part of the time. These drills, cars and rooms, and similar excess resources, are often referred to as "structural waste". This is of course not waste in the traditional sense, but it constitutes a form of waste in the sense that these are idle, yet valuable, resources. Therefore, the energy, resources and waste resulting from the production of even more similar objects could have been avoided if we had utilized the objects that already exist more efficiently (cf. McDonough and Braungart 2002).

This is the point of departure for the sharing economy, which has taken the world by storm in recent years (Belk 2014; Botsman and Rogers 2010). There is of course nothing new in people sharing their resources, or in people renting out items they do not use-whether houses, cars or smaller products. Especially in the United States, car sharing has long been commonplace. In recent years, however, the supply of such services has exploded in line with new technological solutions making them possible (e.g., Sundararajan 2013). Numerous technological platforms, or apps, have emerged and challenged the established players in the industry. The most famous services are perhaps Uber, which competes with taxis; Airbnb, which competes with hotels; and eBay, which sells all conceivable new and used products in an online marketplace.

The defining characteristic of these sharing-economic services is that they effectively bring together people who have excess resources and those who have a need for using those resources and a willingness to pay for it (Gansky 2010; Stephany 2015). An important prerequisite for an efficient sharing economy is trust between the parties in the transaction (Walter 2017). This is most often solved by the functionality of giving transaction partners a score or assessment after the transaction. Such assessment allows users to know whom they can trust and whom they should avoid. The transaction costs of using such services are decreasing, and as more people use the services, their peers are more likely to adopt the services as well. Sharing services thus serve as third-party entities linking together those who have resources to spare and those who would like to access them. Thereby, such services create a marketplace where 
consumption takes place through access to resources, without all consumers needing ownership of the resources.

An app seems to appear for any business opportunity related to shareable resources. The new app Tise facilitates the reuse of fashion clothing; TimeRepublik allows people to share their time with others, and Shyp connects customers who have items they want transported with those who have available vehicles. All these online platforms make it possible for people to make resources they do not use accessible such as their time, space in their cars, houses, ski equipment or drills they might have to spare.

The sharing economy is booming, but it is no stranger to controversy. This particularly applies to the question of workers' rights and taxation related to such services (Sundararajan 2016). Uber has, for example, been in the spotlight regarding labor law, and Airbnb has been criticized for the effects of its service on housing prices in densely populated urban areas. Thus, the social footprint of the sharing economy is ambiguous, but there can obviously be environmentally beneficial aspects of consuming in a way that allows more people to use the same resources. For sharing to take place under proper conditions, such markets need regulation in line with other markets. Currently, developments are happening so fast that legislative efforts are lagging behind, which implies that companies aiming to create sharing platforms must be aware of such possible negative aspects.

However, there are not just negative social side effects of the sharing economy. Not at least in a global perspective, these business models have great potential. Although sharing services are most prevalent in Europe and the United States, they have also started to gain a foothold in poorer parts of the world (see, e.g., Karnani 2007). In these markets, there is precisely a great need for products that people cannot afford to buy on their own. An example of a service remedying this is Hello Tractor, which gives farmers in developing countries access to tractors. Through a simple SMS-based system, farmers are given access to rent equipment that can increase their productivity considerably, without having to invest in expensive tractors that obviously stand idle for much of the time. In this way, such sharing services can also have a positive social footprint, not at least in those markets known as the "bottom of the pyramid". 


\subsection{Access to Everything}

Did you know that nearly 1.2 billion people lack access to electricity? In addition, globally, more people have access to mobile phones than to toilets. In 2011, this inspired the founders Kristian Bye and Marius Andresen to start the company Bright Products. The aim was to bring the solar lamp SunBell, which K8 Industrial Design had already designed, to market. The lamp does not only provide light, it can also be used to charge mobile phones, and it can be installed and adjusted to many different types of use. Sveinung met the founders in 2013, right after the company had developed the first prototype of SunBell. It did not take long before a foundation headed by Sveinung invested in Bright, and he joined its board of directors.

Bright attracted early interest from the United Nations, which today is the company's largest customer and SunBell is still its main product. However, the company has developed more products and services that can solve even more problems in the markets where it operates. People at the bottom of the pyramid have great need for several important products and services that they often cannot afford or access (e.g., Prahalad 2012). This includes financial services, healthcare, electricity and education. However, the spread of mobile phones has given poor people access to services they could previously only dream of, precisely because services in banking and finance, electricity, health, entertainment and education are increasingly offered through more accessible digital platforms (Karamchandani et al. 2011). This also provides new opportunities for companies aiming to establish themselves in markets at the bottom of the pyramid. Led by CEO Ingun Berget, Bright therefore entered into a collaboration with Angaza Design in Silicon Valley to use its design of a mobile-based technology that enables customers to pay in installmentsa so-called pay-as-you-go (PAYG) payment model, which is increasingly prevalent in African and Asian markets (Guajardo 2016).

Such a payment model can thus give Bright access to markets wherein potential customers cannot initially afford to buy the product at its full price. These customers have money to spend on kerosene, coal and charging their mobile phones in expensive charging stations. However, even 
though they spend two to three dollars each day on such products and services, they still do not have enough money to buy quality products that can cost anywhere from 50 to up to 200 dollars. This is despite the fact that the products would have paid off for them in a relatively short time.

Bright Products, then, is in the midst of a redesign of its business model, and it experiments with various services and payment models in these markets. The company is also making improvements in environmental performance, for instance, by making changes to product design, production processes and waste management, and it might also be possible to develop business models based on leasing rather than selling. Bright cannot succeed with such changes on its own, and there are a number of alliance partners in these efforts, such as microfinance institutions, distributors, suppliers of technological solutions and designers. A key driver behind this is the service-logic that involves moving from thinking about the company through the lens of the products it offers, and instead emphasize how its offering increases the experienced value for the customer. This implies that Bright goes from being a company that sells solar-powered lamps and mobile chargers to become a company offering services related to energy and beyond.

\section{Profit from Services}

We increasingly take for granted the services we have available through our smartphones. However, a lot has happened in a very short time. For instance, how did a typical office desk look 15 years ago versus today? At the time, most offices had fax machines, books, calculators, pictures, stationery and various types of calendars. Some of these products are still there, but they increasingly face competition from software and smartphone apps. When digital (and analog) services replace physical products, it is often referred to as servitization (e.g., Kastalli and Van Looy 2013). This happens at all levels — from the physical calendars we used to have on our desks now being an app on your phone, to companies that previously bought trucks and other vehicles for their own use now using app-based platforms to pay for access to such vehicles from companies that own fleets of vehicles. 
When applying service-logic to products in this way, it may lead us to end up owning fewer things overall. From a sustainability point of view, this is clearly advantageous. The need for transportation can be reduced when meetings are held via Skype or when 3D printers enable printing components or products where and when they are needed, rather than producing them in low-cost countries and transporting them across the planet. Similarly, there will be less waste when physical products are replaced by digital services, although we should not underestimate the ecological footprint of the server farms that support all business online (see, e.g., Le et al. 2010). We conduct more and more shopping online rather than in physical stores that need large inventories. In addition, an increasing number of business models that contribute to better exploitation of corporate resources are appearing such as the app Too Good to Go. In the Scandinavian markets, this app facilitates transactions between residential customers who can buy food that would otherwise be thrown away from restaurants and cafés that have surplus food from their operations.

Many services that used to imply that we met people are now automatized or digital. This is because in many cases we have gone from being consumers to being prosumers - we take part in producing (or co-creating) the products and services companies offer us (cf. Toffler 1981). We buy our airline tickets online, we check in our own luggage and we scan our electronic tickets before we board the plane. In this way, the airlines reduce their costs by leaving a lot of work to the customers, many of whom prefer the efficiency of "prosuming" the airline travel experience. When we assemble IKEA furniture, we also act as prosumers-we do part of the job that the furniture companies used to do for us. Many of the apps we use, for instance, the maps on our mobile phones and the online services we use to communicate with others, are free. Companies that have offered physical versions of such services must therefore rethink their value propositions, while the companies that offer free services must develop business models that enable them to capture value in other ways (Anderson 2009). Examples of value capture strategies are integration of advertisements into the service or selling data about customers to companies that have use for such data. 


\section{When the Internet Enters Our Things}

Technology in general and Internet technology in particular are important common denominators for the emergence of business models based on service-logic. The development of Bright Products from a productbased to a service-based company is intimately tied to this technological development. Elon Musk has said that he wants to send 4000 satellites into the skies, which in turn can provide worldwide access to WiFi. In that case, the so-called Internet of Things (IoT) will become even more widespread and important than it already is. IoT is the network of physical objects that have built-in electronics, software, sensors and network connections, which render these objects able to collect and exchange data. In the context of big data, machine learning and artificial intelligence, such applications can even be able to learn what your needs are and thereby customize the services they offer. This means that your refrigerator can tell you when the milk has gone sour or that the lights in your house learn your habits and thereby adjust themselves accordingly. Such a system can also be remote-controlled by means of various applications and can thus be enriched with information from the increasingly large amounts of data collected in real time. Ultimately, such systems support smarter decisions that are constantly self-enhancing because they learn while being in use.

For instance, when Tesla had a problem with a low rear axle on its cars that were driving around on American roads, its engineers solved it by pushing a button on a computer in Tesla headquarters. The next time Tesla owners started their cars, the cars were raised the necessary number of centimeters automatically. This was done without the cars being called back to the Tesla shops, which many other carmakers had to do when encountering similar problems. Tesla can remotely control such changes since all its cars are connected to Tesla's servers. It is estimated that in the near future, Io $\mathrm{T}$ will be built into several billion objects, such as the solar lamps and house systems offered by Bright Products. This technology is already affecting the way we live, work and organize our cities, and the impact will become considerably stronger. For example, companies like Cisco and IBM are collaborating with governments 
around the world to develop so-called smart cities. The concept refers to cities that are designed in such a way that essential services are interconnected and can be coordinated automatically and in real time by means of sensors, big data and digital decision support systems. Such systems can allow public transportation to be planned in real time based on information about who is where and their movements at any given time. Similarly, it can allow for full control over water and energy consumption, waste disposal systems and so on. In this way, the various services in the city are becoming increasingly connected and will be able to automatically adapt to each other. Such planning has an obvious potential for successfully managing resources in smarter ways, thereby reducing overall resource consumption.

An important aspect of IoT is that it takes us from a world wherein products are static to a world wherein they serve as dynamic services that can be changed, upgraded and improved on as they are used. It also enables automatic customization of services through the application's learning of the user's preferences. Previously, when we bought products, we had to bring them to the manufacturer or other companies if we wanted to modify them. IoT provides infrastructure that enables the improvement of products in real time, as in the Tesla example. Thus, products and services can do a better and better job of solving our problems over time. An "intelligent refrigerator" that tells us when milk turns sour, and which maybe even orders new milk from the online store without asking us first, resembles a service more than a product.

Both Apple's iPhone Upgrade Program and Bright Products' new business model are stories of companies that move from being providers of products to become service providers aiming to solve the problems of its customers. As we have seen, the value propositions of these companies typically look different from those of their previous business models, and usually it necessitates other types of payment models for making their business models profitable. One important characteristic of such business models, however, is that they enable smarter use of resources. In this way, they play an important role in changing business from being linear to being more circular. 


\section{References}

Anderson, C. (2009). Free: The future of a radical price. New York, NY: Random House.

Baines, T. S., Lightfoot, H. W., Benedettini, O., \& Kay, J. M. (2009). The servitization of manufacturing: A review of literature and reflection on future challenges. Journal of Manufacturing Technology Management, 20(5), 547-567.

Belk, R. (2014). You are what you can access: Sharing and collaborative consumption online. Journal of Business Research, 67(8), 1595-1600.

Bocken, N. M., de Pauw, I., Bakker, C., \& van der Grinten, B. (2016). Product design and business model strategies for a circular economy. Journal of Industrial and Production Engineering, 33(5), 308-320.

Bocken, N. M. P., Short, S. W., Rana, P., \& Evans, S. (2014). A literature and practice review to develop sustainable business model archetypes. Journal of Cleaner Production, 65, 42-56.

Botsman, R., \& Rogers, R. (2010). What's mine is yours. The rise of collaborative consumption. New York, NY: HarperCollins.

Dhebar, A. (2016). Razor-and-Blades pricing revisited. Business Horizons, 59(3), $303-310$.

Gansky, L. (2010). The mesh: Why the future of business is sharing. London: Penguin.

Guajardo, J. A. (2016). Pay-as-you-go business models in developing economies: Consumer behavior and repayment performance. Available at SSRN.

Karamchandani, A., Kubzansky, M., \& Lalwani, N. (2011). Is the bottom of the pyramid really for you. Harvard Business Review, 89(3), 107-111.

Karnani, A. (2007). The mirage of marketing to the bottom of the pyramid: How the private sector can help alleviate poverty. California Management Review, 49(4), 90-111.

Kastalli, I. V., \& Van Looy, B. (2013). Servitization: Disentangling the impact of service business model innovation on manufacturing firm performance. Journal of Operations Management, 31(4), 169-180.

Le, K., Bilgir, O., Bianchini, R., Martonosi, M., \& Nguyen, T. D. (2010, June). Managing the cost, energy consumption, and carbon footprint of internet services. In ACM SIGMETRICS performance evaluation review (Vol. 38, No. 1, pp. 357-358). ACM.

Lusch, R. F., \& Vargo, S. L. (2012). Service-dominant logic. Cambridge: Cambridge University Press. 
McDonough, W., \& Braungart, M. (2002). Cradle to cradle: Remaking the way things work. New York, NY: North Point Press.

Mont, O. K. (2002). Clarifying the concept of product-service system. Journal of Cleaner Production, 10(3), 237-245.

Ng, I., Parry, G., Smith, L., Maull, R., \& Briscoe, G. (2012). Transitioning from a goods-dominant to a service-dominant logic: Visualising the value proposition of Rolls-Royce. Journal of Service Management, 23(3), 416-439.

Prahalad, C. K. (2012). Bottom of the pyramid as a source of breakthrough innovations. Journal of Product Innovation Management, 29(1), 6-12.

Stahel, W. R. (2016). The circular economy. Nature, 531(7595), 435.

Stephany, A. (2015). The business of sharing: Making it in the new sharing economy. London: Palgrave Macmillan.

Sundararajan, A. (2013). From Zipcar to the sharing economy. Harvard Business Review, 1.

Sundararajan, A. (2016). The sharing economy: The end of employment and the rise of crowd-based capitalism. Cambridge, MA: MIT Press.

Toffler, A. (1981). The third wave. New York, NY: Bantam Books.

Tukker, A. (2004). Eight types of product-service system: Eight ways to sustainability? Experiences from SusProNet. Business Strategy and the Environment, 13(4), 246-260.

Walter, E. (2017). Trust in the sharing economy. Can trust make or break a sharing enterprise? Anchor Academic Publishing.

World Bank. (2015). Services, etc., value added (\% of GDP). Retrieved May 11, 2015, from http://data.worldbank.org/indicator/NV.SRV.TETC.ZS. 
Open Access This chapter is licensed under the terms of the Creative Commons Attribution-NonCommercial-NoDerivatives 4.0 International License (http:// creativecommons.org/licenses/by-nc-nd/4.0/), which permits any noncommercial use, sharing, distribution and reproduction in any medium or format, as long as you give appropriate credit to the original author(s) and the source, provide a link to the Creative Commons license and indicate if you modified the licensed material. You do not have permission under this license to share adapted material derived from this book or parts of it.

The images or other third party material in this chapter are included in the chapter's Creative Commons license, unless indicated otherwise in a credit line to the material. If material is not included in the chapter's Creative Commons license and your intended use is not permitted by statutory regulation or exceeds the permitted use, you will need to obtain permission directly from the copyright holder.

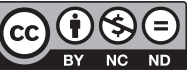

